\title{
Breach Geometry Studies Using Depth Detection Technology
}

\author{
Rubens Gomes Dias CAMPOS ${ }^{\bowtie}$ and Aloysio Portugal Maia SALIBA \\ UFMG, Hydraulic Engineering and Water Resources Department, Belo Horizonte, MG, Brazil \\ $\triangle$ rubensengenheiro2004@yahoo.com.br
}

\begin{abstract}
The use of a 3D Scanner allowed the acquisition of dam breach geometry on a physical model. This technique is widely used in interactive movement entertainment and was adapted for this study's aims. The conceived apparatus collected breach geometry from a physical model built to evaluate a channel's cascade dam break. The 3D Scanner mapped breach surfaces and allowed the input on image processing software to generate its digital surface and elevation contours, reducing measurement errors since it is a non-contact method. An apparatus was then developed to enable accurate scanning since this feature's original function was motion detection. The apparatus consisted of a platform assembled on rails, installed over channel walls, supporting a Kinect II (Microsoft Corporation ${ }^{\circledR}$ 3D Scanner), connected to a notebook.
\end{abstract}

Keywords: 3D Scanner, physical models, cascade dam breach geometry, breach equation, breach formation time.

\section{INTRODUCTION}

Obtaining undisturbed test geometries surfaces in physical models is an arduous task, as incautious measurement can disturb the surface, and a non-contact method is preferred. Also, breach geometry characterization needs three-dimensional (3D) scanning, many times too expensive, especially in developing countries' hydraulic laboratories. This research used a low-cost 3D scanning technique in this regard. The overall cost of the scanning apparatus was about US\$ 2000 , including the notebook.

\section{SCANNING METHODOLOGY}

The scanning equipment used for surveying dams' models and their breaches was the Kinect II 3D scan sensor (Microsoft Corporation ${ }^{\circledR}$ ), similar to developed by Marinello et al. (2015). 
The Kinect II 3D scanning sensor includes an infrared laser emitter, an infrared camera, and a RGB camera. Depth information came from a triangulation process, where a diffraction grid divides the infrared laser into a specific pattern projected into the scene. The pattern is collected by the infrared camera and compared to the projected one. Local offsets generate a disparity map, where larger displacement values correspond to the sensor's farther positions and, conversely, smaller values correspond to positions closer to the sensor.

According to Gonzalez-Jorge et al. (2015), the Kinect II 3D scanning sensor has an accuracy ranging from 0.3 to $7.5 \mathrm{~mm}$ for a surveying distance from 1.0 to $4.0 \mathrm{~m}$. The scanning survey distance on this research was between 1.0 and $2.0 \mathrm{~m}$, with depth measurements' errors between 0.3 and $0.4 \mathrm{~mm}$. Scanning measurements showed values precisely equal to scale measured channel width, demonstrating that errors were below $1 \mathrm{~mm}$ (the smallest scale division). This error interval is quite reasonable for these dam breach geometry analyses. Figure 1a shows a physical model breach resulting from a cascade dam break, and Fig. 1b shows this breach 3D scanned (Campos 2020).

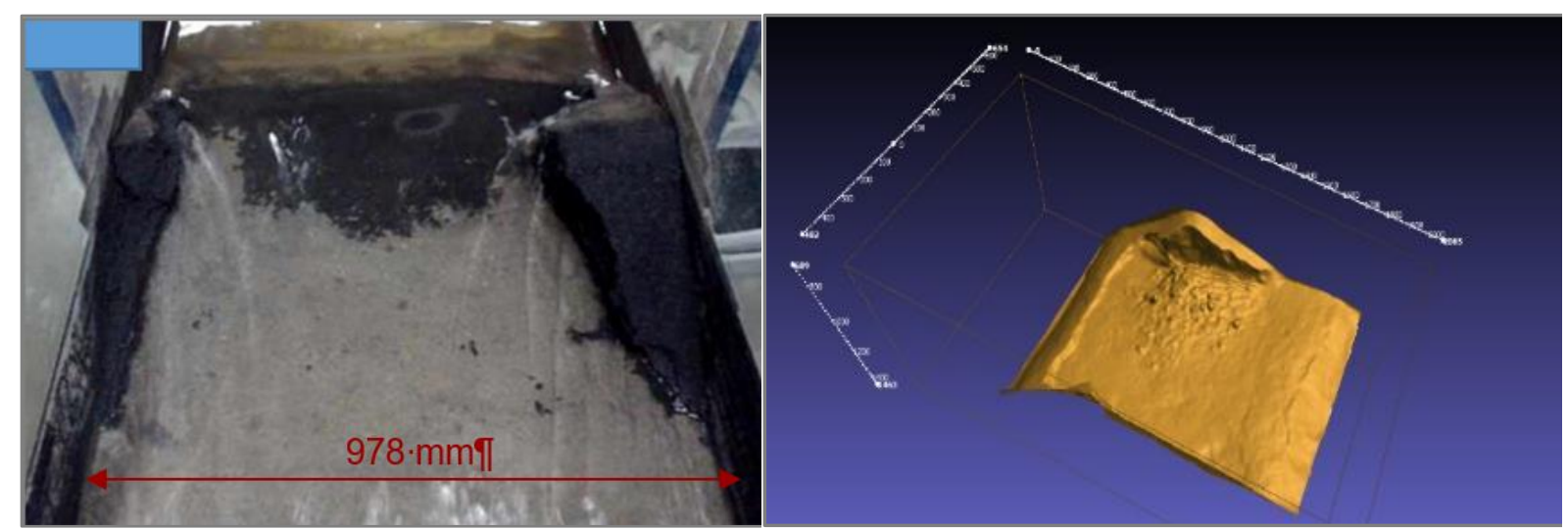

Fig. 1. Physical model cascade breach at time 4 minutes 16 seconds: (a) downstream view, and (b) final developed breach 3D scanned (Campos 2020).

A few software must be installed in a microcomputer to use Kinect II 3D as a scanning device, such as 3D Builder (Microsoft Corporation ${ }^{\circledR}$ ) for scanning input, Kinect SDK 1.8, OpenNI 2, NiTE 2.2, and Skanect for notebook compatibility. A Scanner 3D Kinect II adapter cable was purchased to connect this sensor to the notebook's USB input.

Acknowledgments. We express our gratitude to Professor Márcio Benedito Baptista (In memoriam) and to the Hydraulics Research Center (Centro de Pesquisas Hidráulicas - $\mathrm{CPH}$ ) of the Federal University of Minas Gerais (UFMG) that had held this research.

\section{References}

Campos, R.G.D. (2020), Proposta de uma metodologia para obtenção de parâmetros de brechas em rupturas de barragens em cascata utilizando modelagem física, Ph.D. Thesis, UFMG, $230 \mathrm{pp}$. (in Portuguese).

Gonzalez-Jorge, H., P. Rodríguez-Gonzálvez, J. Martínez-Sánchez, D. González-Aguilera, P. Arias, M. Gesto, and L. Díaz-Vilariño (2015), Metrological comparison between Kinect I and Kinect II sensors, Measurement 70, 21-26, DOI: 10.1016/j.measurement.2015.03.042. 
Marinello, F., A. Pezzuolo, F. Gasparini, J. Arvidsson, and L. Sartori (2015), Application of the Kinect sensor for dynamic soil surface characterization, Precision Agric. 16, 601-612, DOI: 10.1007/ s11119-015-9398-5.

Received 22 March 2021

Accepted 12 April 2021 